\title{
Virtualização esportiva e os novos paradigmas para o movimento humano
}

\author{
Bruno Medeiros Roldão de Araújo 1,2 \\ Clara Maria Silvestre Monteiro de Freitas ${ }^{2,4}$ \\ Iraquitan de Oliveira Caminha ${ }^{3,4}$ \\ Priscilla Pinto Costa da Silva ${ }^{2}$ \\ ${ }^{1}$ Grupo de Pesquisa Desenvolvimento Humano, Aprendizagem e Educação do Campo, \\ Universidade Federal de Campina Grande, Sumé, PB, Brasil \\ ${ }^{2}$ Grupo de Estudos e Pesquisas Sócio-Culturais: o indivíduo em educação física e \\ desporto, ESEF da Universidade de Pernambuco, Recife, PE, Brasil \\ ${ }^{3}$ Centro de Ciências da Saúde, Departamento de Educação Física, Universidade Federal \\ da Paraíba, João Pessoa, PB, Brasil \\ ${ }^{4}$ Programa Associado de Pós-Graduação em Educação Física - UPE/UFPB
}

\begin{abstract}
Resumo: $O$ esporte virtual proveniente das novas vivências eletrônicas se revela como um importante fenômeno do processo de virtualização das experiências corporais. Tal processo mostra que as interações entre o que é atual e virtual extrapolam as barreiras de tempo e espaço intensificando as sensações em novas formas de vivências esportivas. O objetivo foi analisar os processos de virtualização esportiva, ligados aos jogos eletrônicos, sua interferência na cultura corporal de movimento e quais as possíveis implicações para a Educação Física. A metodologia foi a qualitativa descritiva de campo, em que foram realizadas entrevistas semi-padronizadas com 30 atores sociais, entre 11 e 15 anos de idade, do Ensino Fundamental II de duas escolas da rede pública e privada do estado da Paraíba e os dados foram tratados através da Análise de Conteúdo de Bardin. A análise dos discursos apontou os jogos eletrônicos como um relevante instrumento de socialização, diversão e aprendizagem.
\end{abstract}

Palavras-chave: Jogos de Vídeo. Educação Física. Interface Usuário-Computador.

\section{Sportive virtualization and the new paradigms for the human movement}

\begin{abstract}
The coming of the new virtual sports experiences electronic reveals an important phenomenon in the process of virtualization of body experiences. This process shows that the interactions between what is actual and virtual transcend the barriers of space and time intensifying the sensations in new forms of sports experiences. The objective was to analyze the processes of sports virtualization, in relation to videogames, its interference in the culture of body movement and its possible implications for Physical Education. The methodology was a field research with descriptive qualitative approach. Semi-standardized interviews were accomplished with 30 social actors, between 11 and 15 years of age in middle school (upper primary or lower secondary) in two public schools and private schools in the state of Paraiba - Brazil and the data were processed through Bardin's Content Analysis. The discourse analyses proved the games to be an important instrument of socialization, fun and learning.
\end{abstract}

Key Words: Video Games. Physical Education. User-Computer Interface.

\section{Introdução}

Esta pesquisa é fruto de uma análise da dinâmica da evolução tecno-científica em andamento, que apresenta novas e indefinidas fronteiras para a convivência humana e que, por meio de suas conseqüências na vida social, identificamos uma constante e rápida evolução cultural em que a cibercultura se delineia no ciberespaço da rede mundial de computadores e dos mundos virtuais dos jogos eletrônicos ${ }^{1}$. Estes

\footnotetext{
1 Neste estudo o termo "jogos eletrônicos" se refere aos jogos virtuais, videogames ou simplesmente games jogados em consoles (plataformas de jogo), computadores e similares. Os termos são utilizados como sinônimos.
}

espaços virtuais são fontes e também produto do processo de virtualização, que constitui a base da mutação em curso. Este processo enraíza-se por diversos campos, atingindo o movimento humano e consequentemente a cultura deste movimento concretizada e sistematizada nos esportes, o que causa uma necessidade de reflexão destas questões na Educação Física. Esta preocupação apesar de pouco estudada pela área, foi percebida e investigada desde os primórdios da popularização dos videogames, mas um novo cenário se abre com a chegada dos 
equipamentos hápticos ${ }^{2}$ às plataformas de jogos eletrônicos e o advento dos exergames (JIN, 2010; ROSENBERG; DEPP; VAHIA; REICHSTADT; PALMER; KERR; NORMAN; JESTE, 2010) jogos baseados no movimento do ciberjogador/ciberatleta, no qual o corpo é a própria ferramenta de execução das ações propostas nos mundo virtuais.

O esporte virtual proveniente das novas vivências eletrônicas se mostra importante fenômeno dentro do processo geral de virtualização, que acontece cada vez mais rápido, fazendo com que as interações entre o que é atual/real e o que é virtual extrapolem as barreiras de tempo e espaço intensificando as sensações numa vivência esportiva jamais vista, as vivências virtuais. Estas vivências se configuram numa "virtualização esportiva", na qual a influência midiática vem interferindo também na cultura corporal de movimento, pois os jogos, notadamente os esportivos virtuais, estão intimamente ligados à cultura infanto-juvenil atual.

A cultura corporal de movimento é definida por Betti (2001, p.156) como "aquela parcela da cultura geral que abrange as formas culturais que se vêm historicamente construindo, nos planos material e simbólico, mediante o exercício da motricidade humana". A partir de tal visão, podese observar que a inclusão dos jogos eletrônicos esportivos no campo da motricidade, traz um novo paradigma para o movimento humano, o da virtualização por meio das imagens de síntese na tela e sua imediata atualização na ação do gamer.

Diante deste cenário, a investigação objetivou analisar os processos de virtualização esportiva, vinculados aos jogos eletrônicos, sua interferência na cultura corporal de movimento e quais as possíveis implicações para a Educação Física e o Esporte.

\section{Os jogos eletrônicos a cibercultura e a quebra dos paradigmas de imobilidade corporal}

A espetacularização esportiva pelos meios de comunicação da mídia, notadamente a televisiva e a variedade de games, difundem o esporte e têm levado as pessoas novos conhecimentos sobre diversas modalidades, antes só conhecidas por profissionais especializados ou aqueles que os praticavam e/ou viviam numa cultura que valorizava determinada modalidade. Este processo torna o virtual mais presente que a prática corporal de determinados esportes,

\footnotetext{
2 Que utilizam o sistema háptico, que é um sistema de percepção sensório-motor que está relacionado com a percepção das texturas, dos movimentos e forças por meio da coordenação de esforços dos receptores dos sentidos do tato, da visão, da audição e a propriocepção (SANTAELLA, 2004).
}

levando a novas conformações socioculturais esportivas.

Neste sentido, Azevedo (2004) e Gama (2005a) apontaram que a partir do desenvolvimento do proceso de virtualização esportiva por meio dos games, surgiram campeonatos organizados por empresas do ramo e consequentemente a profissionalização dos ciberatletas. Feres Neto (2006) apresenta dados da Córeia do Sul, país em que praticamente um terço da população está inscrita em jogos on-line ${ }^{3}$, no qual surgiram os primeiros videogamers profissionais, que chegam a ganhar US\$100 mil por ano, gerando um fenômeno que culminou em Campeonatos Mundiais de Videogame, como o World Cyber Games, campeonato anual que reúne ciberatletas de mais de 50 países. As implicações sociais de tais processos ainda não estão bem delimitadas, mas trazem novos entendimentos ao processo civilizatório que nas sociedades ocidentais estão intimamente ligados ao desenvolvimento e sistematização dos esportes, conforme apontam Elias e Dunning (1995).

Para os referidos autores, o autocontrole oriundo das atividades reconhecidas como esporte leva a um estado de equilíbrio de tensões necessário à formação dos Estados nacionais modernos, eles seriam controles autônomos surgidos na rotina da própria vida social a qual o indivíduo está imerso, neste sentido é um controle criado dentro de si, para melhor vivência em sociedade, mas que advém da própria, ou seja, um autocontrole controlado pela sociedade. Portanto a prática e profissionalização de ciberesportes, por serem novas maneiras de vivências para o controle das tensões sociais, levam a novas formas de organização e entendimento sociocultural dos indivíduos.

Diante deste cenário, há os jogos eletrônicos que ao fazerem parte da cultura lúdica e esportiva contemporânea, formam uma nova conformação cultural marcada pelos avanços tecnológicos digitais, surgidos no âmbito das cibercidades. Confirmando esta posição, Betti (1998, p. 149) enfatiza que na "cultura esportiva das crianças e dos jovens tomam parte tanto o esporte, como prática corporal 'real', como as formas 'virtuais' do esporte telespetáculo, dos jogos de videogame e computador". Assim os jogos eletrônicos vêm formando a cultura esportiva contemporânea, levando, juntamente a outras influências das Tecnologias da Informação e Comunicação - TIC à formação do que se tem chamado de cibercultura.

\footnotetext{
${ }^{3}$ Estes games são os jogados em rede via Internet.
} 
Para Lemos (2003, p.12), a cibercultura é a "forma sociocultural que emerge da relação simbiótica entre a sociedade, a cultura e as novas tecnologias de base micro-eletrônica que surgiram com a convergência das telecomunicações com a informática". Por outro lado, Lévy (1999), define a cibercultura como o conjunto de técnicas intelectuais e materiais, de atitudes, valores, modos, pensamentos, práticas e comportamentos que se desenvolvem no ambiente do ciberespaço, ou seja, é tudo que o homem produz quando está imerso numa realidade virtual, de comunicação via satélite, celulares, vídeo conferências e comunidades virtuais.

Com o surgimento desta nova realidade, não se têm necessariamente a substituição de antigas práticas de lazer, mas a reconfiguração das mesmas, por exemplo, antes os jovens se reuniam nos campos de várzea para "jogar uma pelada", atualmente se reúnem nas $L A N^{4}$ Houses para jogarem "uma pelada virtual" de Pro Evolution Soccer ou Fifa Soccer (os mais populares).

Os jogos eletrônicos se apresentam como uma alternativa crescente de lazer, conforme apontam os estudos de Gama (2005b), Reis e Cavichiolli (2008). Contudo, sua prática, a princípio, sinaliza uma descorporização das práticas esportivas nas novas gerações, trazendo malefícios aos seus praticantes, conforme apontam os estudos de base epidemiológica, que normalmente associam os jogos eletrônicos à dependência psíquica ou à inatividade física, levando a comorbidade como apontam os estudos de Abreu, Karam, Góes, e Spritzer (2008), Mark e Janssen (2008), Rinaldi, Pereira, Macedo, Mota, e Burini (2008), Setzer (2008) e Vasques e Lopes (2009). Mas, com o desenvolvimento das tecnologias aplicadas aos jogos eletrônicos, o quadro esta mudando, pois há games que envolvem o movimento de vários segmentos corporais (exergames) e o corpo pode experimentar fisicamente sensações em relação a objetos e eventos virtuais.

Em 2006, a empresa japosesa Nintendo lançou o console Wii que possui um joystick com sensores que permitem o corpo do jogador interagir com o game, ao movimentá-lo de um lado para o outro. E com o lançamento do periférico Balance Board em 2008, uma plataforma que serve como base ao jogador, com sensores que captam os movimentos e os trasferem ao game, o Wii transportou os jogos

\footnotetext{
4 Sigla de: Local Area Network, uma rede local de computadores que podem também estar conectadas via Web.
}

eletrônicos para o campo da atividade física, por meio dos jogos que se baseiam no movimento corporal dos jogadores. Este videogame proporciona uma autêntica atividade fisica, sendo ultilizado em academias de ginástica e clínicas de Fisioterapia. O que demonstra uma quebra de antigos paradigmas de descorporização nestas práticas.

Confirmando que os games e o movimento corporal caminham juntos, foi anunciado, pela Microsoft, um sensor de movimentos para jogos e plataformas, durante a Electronic Entertainment Expo (E3) de 2009, a maior feira de jogos eletrônicos do mundo, realizada anualmente em Los Angeles, Califórnia, Estados Unidos. O sensor de movimento inicialmente apresentado como Project Natal foi lançado em Novembro de 2010 para a plataforma Xbox 360, nomeado de Kinect permite que o jogador utilize seu próprio corpo como joystick, interagindo diretamente com - game. O sistema, que utiliza uma espécie de câmera com sensor, capta os movimentos do jogador e os reproduz, em tempo real, dentro da interface do jogo, sendo também um poderoso sistema de reconhecimento de voz e de expressão facial. O que demonstra neste sentido, uma evolução considerável em relação ao Eye Toy, sistema proposto pela Sony em 2003 para a palataforma Playstation 2, que utiliza câmera de captação de movimentos como sistema de Realidade Aumentada (RA) para interação com games. Segundo Henderson e Feiner (2010) a RA conta com os gestos do usuário para a interação física/virtual, o que demonstra a significativa interação do corpo do usuário/jogador no espaço virtual dos jogos eletrônicos que se utilizam desta tecnologia.

Vale salientar que a virtualização esportiva não se restringe aos exergames, tendo sim importância singular desde as primeiras virtualizações esportivas via games, a exemplo do Pong, popular "jogo virtual de tênis" nas décadas de 1960 e 1970. Neste estudo são focados todas as experiências de virtualização esportiva vivenciadas pelos atores sociais, independentemente de serem as formas tradicionais, hápticas ${ }^{5}$ e/ou exergames.

\section{Metodologia}

A metodologia adotada foi a qualitativa descritiva de campo, em que foram realizadas entrevistas $^{6}$ semi-estruturadas com 30 Atores

\footnotetext{
5 Sistema de vibração que simula eventos virtuais, comercializados como item de série nos joysticks a partir do final da década de 1990, após o lançamento do acessório Rumble Pak da Nintendo.

${ }^{6}$ Roteiro de Entrevista individual semi-estruturada, adaptado a partir de Moita (2006).
} 
Sociais, entre 11 e 15 anos de idade, do Ensino Fundamental II de duas Escolas da rede pública e privada do Estado da Paraíba. A organização das informações advindas das entrevistas passou em um primeiro momento, pela análise dos dados referentes às questões fechadas, as quais foram tratadas segundo a estatística descritiva, por meio de programa específico Statistical Package for the Social Sciences (SPSS v.10).

Em um segundo momento, as questões abertas foram tratadas por meio da Análise de Conteúdo de Bardin (2008), que é um recurso a analise categorial, ou seja, delimitação de unidade de codificação, assumida pelo analista que, a partir da totalidade de um texto e em nome de um ideal de objetividade e racionalidade, verifica, com base em critérios de classificação, a frequência ou ausência de itens de sentido (BARDIN, 2008). Os resultados possibilitaram a criação de quadros categóricos analíticos, que conduziram à construção de diagrama. Foram empregados dois softwares: o primeiro foi a Analysis of Qualitative Data - AQUAD 6 (HUBER; GÜRTLER, 2008) utilizado para buscar a frequência das palavras nos discursos dos atores sociais. O segundo software foi o GoDiagram Express for .NET Windows Forms version 2.6.2 (2007), programa utilizado na criação de diagramas.
O presente estudo é fruto de projeto encaminhado ao Comitê de Ética em Pesquisa (CEP) da Universidade de Pernambuco com Certificado de Apresentação para Apreciação Ética - CAAE no . 0189.0.097.000-08. O Termo de Consentimento Livre e Esclarecido (TCLE) foi assinado pelos pais e/ou responsáveis, com base nas diretrizes éticas da pesquisa com seres humanos, recomendadas pela Comissão Nacional de Ética em Pesquisa (CONEP), Resolução 196/96 do Conselho Nacional de Saúde (BRASIL, 2003), respeitando as quatro referências básicas da bioética: autonomia, não maleficência, beneficência e justiça.

\section{Resultados}

O Diagrama 1 apresentado a seguir, tem como suporte metodológico a análise de conteúdo de Bardin (2008) desenvolvida à luz da justificativa dos atores sociais em relação a aprendizagem esportiva nos games. Na sua construção foram agrupados conceitos relativos às categorias analíticas objeto dos discursos dos atores sociais. As caixas de texto assinaladas na cor cinza referem-se às subcategorias oriundas da categoria aprendizagem. As variáveis ligadas às subcategorias estão representadas nas caixas de texto de cor branca.

Diagrama 1. Aprendizagem sobre esportes por meio dos games nas Escolas Pública e Privada - Campina Grande-PB - 2009.

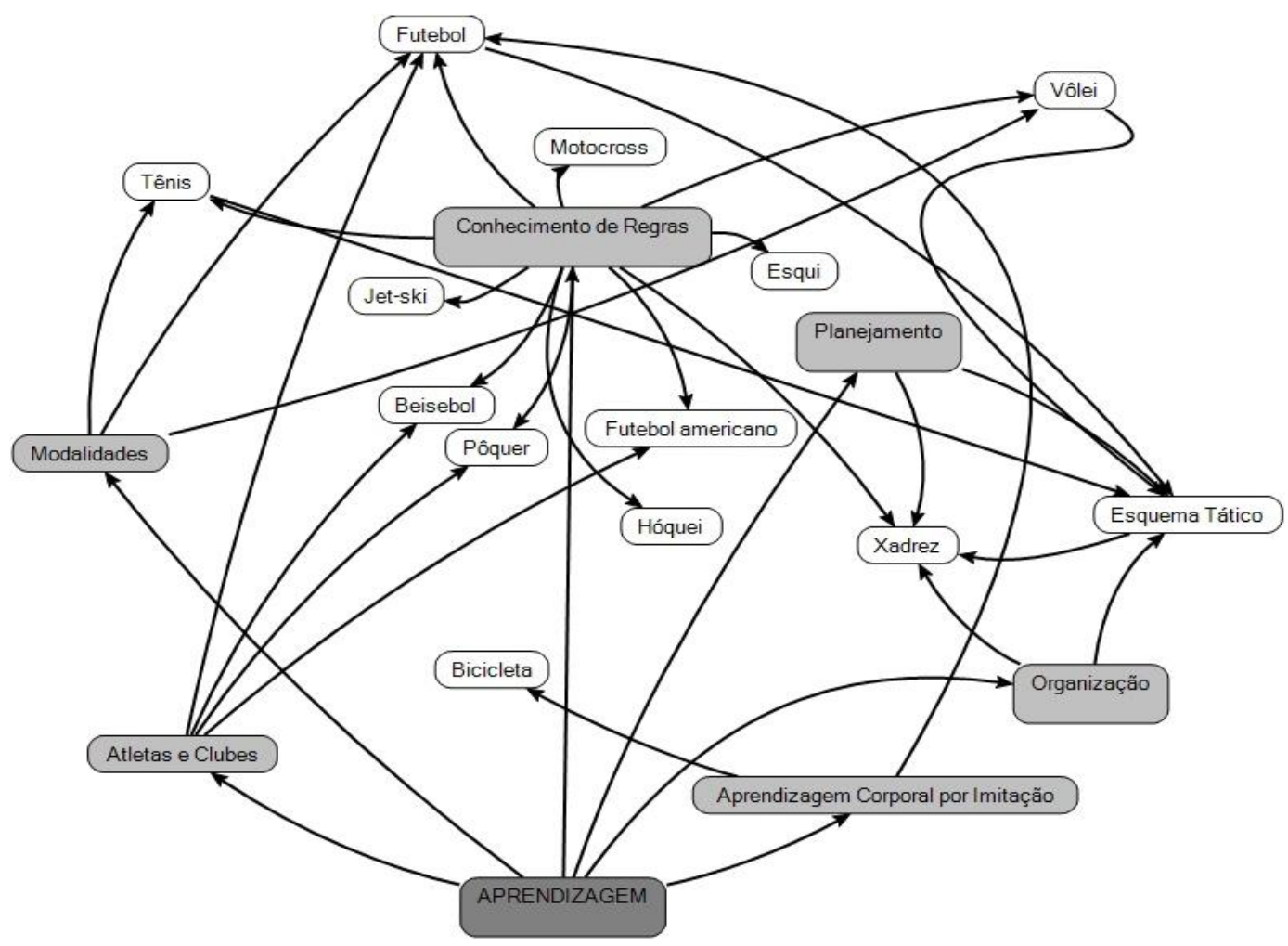




\section{Discussão}

O Diagrama 1 apresenta as principais categorias analíticas segundo as frequências mais representativas, na qual a aprendizagem de esportes por meio dos jogos eletrônicos foi vinculada principalmente ao "conhecimento das regras", seguida da "noção de planejamento", "conhecimento sobre diferentes modalidades esportivas", noção de "organização", "conhecimento de atletas e clubes" e "aprendizagem corporal por imitação".

Elencam-se a seguir os principais resultados advindos do aprendizado relacionado à subcategoria "modalidades", direcionadas ao tênis, futebol e vôlei. A propósito do aprendizado sobre "atletas e clubes", as falas dos atores sociais revelaram que estão vinculados ao futebol, beisebol, pôquer e futebol americano, obviamente que o aprendizado do nome dos atletas e dos clubes passa pelo conhecimento da modalidade em si, entretanto as subcategorias foram distintas, representando o que ficou explícito nos discursos.

Neste sentido, Pereira (2006) aponta que, por meio dos jogos eletrônicos, os jovens e as crianças aprendem o nome dos jogadores dos grandes clubes europeus de futebol, pois 0 videogame se tornou o "novo álbum de figurinhas", que permite criar, com um realismo de imagens e sensações cada vez maior, um mundo de inúmeras formas de interação, no qual os games se tornam algo distante "do estigma de diversão solitária, os jogos cada vez mais abrem a possibilidade de interação com outros jogadores em rede, estejam eles no computador ao lado ou do outro lado do oceano" (PEREIRA, 2006, p. 4).

No tocante a subcategoria "conhecimento das regras" também está fortemente relacionada às subcategorias discutidas, mas um ponto a se destacar é a possibilidade de conhecer e aprender as regras de esportes de difícil acesso no Brasil, seja por fatores econômicos ou culturais, conforme revela a fala:

Sim. Aprendi algumas regras que não entendia no futebol e alguns esportes que não existe aqui, como esqui na neve, Jet-ski, MotoCross. (ATOR SOCIAL № 18, Escola pública).

Este aprendizado, embora passe apenas pelo conhecimento das regras de determinadas modalidades, aparece como um importante meio para auxiliar o aprendizado do conteúdo esporte nas aulas de Educação Física Escolar, o que estaria levando a novos delineamentos paradigmáticos para a Área.

A aprendizagem vinculada ao "planejamento" e à "organização" está ligada ao xadrez e aos esquemas táticos do vôlei e do futebol, conforme aponta as seguintes falas:

Aprendi os esquemas 4-4-2, essas coisas de mudar posição de jogador [...] 3-5-2, 3-6-1, sei tudinho. (ATOR SOCIAL № 02, Escola privada).

Primeiro faço análise do jogo e quando estiver no ponto certo é que jogo, no futebol mesmo olho se as laterais e zaga estão abertas, eu que ajeito. (ATOR SOCIAL № 27, Escola pública).

O desenvolvimento da capacidade de "planejamento" e "organização" oriunda da prática dos jogos eletrônicos demonstra ser uma aprendizagem que pode ser absorvida em situações da vida, não somente nos campos virtuais e/ou físicos. Aguilera e Mendiz (2003) defendem que os saberes oriundos da prática dos games estão relacionados ao hábito de leitura, desenvolvimento do raciocínio lógico, capacidade de observação, capacidade de localização, orientação espacial, capacidade de resolução de problemas e planejamento de estratégias, estes saberes são também aprendidos nos jogos eletrônicos e passam a fazer parte da vida dos sujeitos jogadores.

Diante deste cenário, foi possível inferir que os atores sociais da Escola pública, apresentaram um maior conhecimento de modalidades por meio da virtualização esportiva e um repertório motor mais amplo, uma vez que as falas dos atores sociais de ambas as escolas revelaram que os estilos de "games de ação desportiva" mais jogados estavam relacionados à prática real destes esportes e/ou a vontade de praticá-los, o que muitas vezes se mostrou acessível apenas na forma virtual dos jogos eletrônicos, sobre isso se destaca a seguinte fala:

Futebol Bomba Patch 5.1, porque é o jogo mais popular e gosto muito de futebol da vida real. Tênis, vôlei de praia, gosto porque são os esportes que eu mais gosto, apesar de nunca ter jogado tênis na vida real. (ATOR SOCIAL № 30, Escola pública).

A subcategoria "Aprendizagem por Imitação Corporal" interessa especialmente por sua relação com o desenvolvimento da cultura corporal de movimento, o que pode ser ilustrado nas seguintes falas: 
Tento realizar na vida real alguns lances que aprendi nos games. (ATOR SOCIAL № 17, Escola pública).

Sim. A pessoa na quadra, quando há impedimento, aprendi no videogame [...].(ATOR SOCIAL № 22, Escola pública).

Sim. Já, bicicleta não sabia empinar, aprendi no game e hoje em dia sei fazer nos dois, primeiro no videogame e desde os sete anos aprendi na bicicleta mesmo. (ATOR SOCIAL № 28, Escola pública).

Futebol, [...]. A pessoa aprende a jogar certas jogadas como pedalar, dar balão, os quais tento realizar quando jogo futebol de verdade. (ATOR SOCIAL № 19, masculino, Escola pública).

Neste aspecto, os discursos refletem um processo de criação do movimento humano, por meio da reprodução de vivências não corporais, em forma de motricidade humana (esporte e/ou jogo) agente e criadora da cultura conforme Sérgio (2000). Neste sentido confirmando as idéias de Betti (1998), Brougére (1995), Costa e Betti (2006) ao afirmar que as crianças e jovens vão buscar na cultura a qual estão imersos 0 mote para suas brincadeiras, que por sua vez sofrem influência midiática, fazendo com que as formas virtuais também componham a cultura esportiva desses jovens, participando assim do desenvolvimento de sua própria cultura corporal de movimento.

Este processo não ocorre por simples imitação de gestos, afinal os homens "continuamente atribuem significados culturais às suas ações, variando as formas de execução, transformandoas, criticando-as e executando-as com objetivos os mais variados possíveis" (DAOLIO, 2002, p.102). Neste sentido, pode-se compreender os games como matéria para a motricidade humana e a mobilidade como produto final do movimento humano, permeado pelas transformações culturais que os significados daquela ação requerem dos sujeitos.

Este tema do movimento passa por um processo de virtualização do corpo proveniente do desenvolvimento das novas tecnologias da informação e comunicação conforme aponta os estudos de Lévy (1996), Santaella (2004) e Herold Junior (2009). Lévy (1996) entende a virtualização do corpo, com um novo estágio de desenvolvimento humano, no qual o "hipercorpo" transcende suas fronteiras físicas, tornando-se compartilhado com os demais numa rede universal. Herold Junior (2009) confirma esta visão ao afirmar que a virtualização do corpo passa pela incorporação de novas informações por meio das TIC de forma rápida e em grande volume, o que ultrapassa o corpo físico humano e Santaella (2004), defende que a imersão do corpo em ambientes virtuais é permeada pela interação do indivíduo com o ciberespaço por meio do sistema háptico, no qual o corpo sensórioperceptivo do cibernauta atualiza-se de maneira a tornar a virtualização algo indissociável do corpo físico, o que corrobora com as suposições deste estudo.

Entendendo que a motricidade humana é construída por meio das interações do indivíduo com ambientes, idéias e/ou movimentos que possam ser atualizados (mobilidade) através de movimentos culturalmente codificados a exemplo do esporte, a virtualização esportiva se apresenta como um novo nível de entendimento para Educação Física contemporânea.

A análise de conteúdo da questão referente à "preferência pelos jogos eletrônicos de ação esportiva" apontou o estilo futebol como a principal subcategoria nas Escolas privada $(80,0 \%)$ e pública $(87,0 \%)$. Na Escola privada sua prática esteve relacionada principalmente ao gosto por jogar, a interação social, o status, a socialização, a diversão, a competição, a interação familiar, jogabilidade e as imagens atraentes, por sua vez na Escola pública a prática dos games de futebol esteve relacionada ao gosto, a diversão, a socialização, a aprendizagem, a interação familiar e a competição. Neste sentido, destacam-se a seguintes falas oriundas da questão "Quais os games de ação desportiva que você mais gosta e como costuma jogar? Por que?":

PES 2008, Winning Eleven 10, porque são os
melhores jogos de futebol, que oferecem a
melhor diversão, são os mais jogados e por isso
cria um status para quem joga bem, afinal onde
você chega e o pessoal tá jogando, se você
sabe jogar logo é bem aceito. (ATOR SOCIAL
№ 12, Escola privada).
O futebol Winning Eleven 11, porque é o mais
jogado, porque futebol meus irmãos jogam e
gosto de enfrentá-los, também têm bons
gráficos. (ATOR SOCIAL № 08, Escola
privada).

A subcategoria status apareceu explicitamente na fala do ator social o12, ao trazer que o saber jogar futebol virtual apresenta o mesmo status que o saber no jogo real, refletindo numa melhor aceitação pelo grupo, promovendo uma interação mais fácil e ampla. Uma leitura sobre esta questão relacionada ao futebol reflete a 
conformação cultural brasileira, em que o futebol aparece como uma verdadeira radiografia da sociedade, fato já apontado por Gilberto Freyre na década de 1930, em artigos para o jornal Diário de Pernambuco.

Para Murad (2009), Freyre é considerado o primeiro grande sociólogo brasileiro e foi um dos primeiros cientistas sociais a reconhecer o futebol como algo fundamental para a compreensão do Brasil. Murad (2009), continua afirmando que, utilizando o modelo apolíneo versus o dionisíaco, oriundo do pensamento de Nietzsche, Freyre comparou os estilos do futebol inglês com o brasileiro e sua metodologia o levou ao conceito filosófico da "equilibração", no qual os antagonismos dentro do futebol, não levam obrigatoriamente ao conflito, por causa de uma "igualdade originária", levando os jogadores a se entender como adversários e não como inimigos, uma lógica educativa, que está na origem do fair play.

Diante deste cenário Freyre localizou o componente "igualdade de oportunidades", algo bem presente no futebol devido ao fato de sua prática ser uma das mais abertas a tipos físicos diferentes, esta dimensão ética se apresenta como forte instrumento para os professores de Educação Física, que podem para isso lançar mão, não somente do jogo real, mas sim do jogo virtualizado que também está fortemente presente na cultura lúdica atual. Nada melhor que o futebol para uma leitura da sociedade brasileira, pois sua compreensão passa pelo futebol seja o de várzea, o de campo ou o da tela eletrônica (televisiva ou por meio dos games).

Sobre a importância do futebol em escala global Hobsbawm (2007, p. 01) afirma que "o futebol sintetiza muito bem a dialética entre identidade nacional, globalização e xenofobia (...) o que faz o futebol popular continua sendo, (...), a fidelidade local de um grupo de torcedores para com uma equipe". Ou seja, esta modalidade reflete a lógica da nacionalidade e de sua linha cada vez mais tênue devido à globalização. Acontecimento que pode ser observado nos games de futebol mais jogados atualmente (PES, Winning Eleven e FIFA Soccer), nos quais são representados os grandes clubes internacionais que são representados por vários jogadores brasileiros fazem a fantasia dos garotos ultrapassarem a barreira nacional, confundindo-a com uma esfera global, algo íntimo ao processo de virtualização. Nesta perspectiva Turkle (2005) aponta que no mundo mediado pelos computadores, o indivíduo é fluido com um "eu" múltiplo e consubstanciado pelas interações em rede, o que para Lévy (1996) induz a um corpo entendido como um ente pertencente à rede social de forma intrínseca, na qual sua fronteira física termina, dando lugar a um corpo virtual sem fronteiras, promovendo mudanças socioculturais, que originam novas formas de compreensão e no caso específico, de entendimento para a motricidade humana.

Em relação à subcategoria "Interação Familiar" nos games, pode-se constatar que elas estão presentes na Escola pública e na Escola privada, devido principalmente aos jogos de futebol eletrônico. Porém, por meio da questão "Com quem normalmente você joga games?", observouse que nenhum ator social da Escola privada afirmou jogar com os pais, enquanto que na Escola pública $(20,0 \%)$ confirmaram jogar em sua companhia. Em relação ao jogar com irmãos, na Escola privada $(26,7 \%)$ afirmaram que sim, enquanto que na Escola pública este índice foi superior atingindo (40,0\%). Neste sentido, inferiuse que a interação familiar foi mais significativa na Escola pública, na qual os alunos pertenciam em sua maioria aos substratos menos favorecidos da sociedade. Algo que pode ser explicado pela escassez de opções de lazer, uma vez que, a área próxima a residência de grande parte dos atores sociais não possuir um espaço público de lazer, restando para estes, seus pais e irmãos o lazer dentro da própria residência, por meio da televisão e dos games.

Conforme identificado no estudo de Weber e Salvador (2005) pode-se compreender a interação familiar, como o relacionamento afetivo entre os membros da família, o envolvimento familiar e as regras de monitoria impostas pelos pais e/ou irmãos mais velhos. Estas regras entendidas como "práticas educativas parentais" (ALVARENGA, 2001; WEBER; SALVADOR, 2005), podem ser "não-coercitivas" (afeto, diálogo, orientação sobre as regras) e/ou "coercitivas" (arbitrariedade, estímulos aversivos como a punição física ou verbal). Práticas estas que podem ser comparadas com as relações sociais propostas por Piaget (1994), que podem ser de "cooperação" ou de "coação social", na cooperação os sujeitos se consideram iguais, desenvolvendo uma consciência autônoma de forma livre por meio da relação com os pares, 
enquanto que na coação social, há imposições advindas de um elemento de autoridade ou prestígio. Diante deste cenário, inferiu-se que a prática dos games com os pais e/ou irmãos se dá de maneira "não-coercitiva/cooperativa", o que segundo os achados de Moita (2006) levam a uma construção de identidades, baseada no respeito, sendo, portanto elemento essencial para o desenvolvimento crítico e autônomo das crianças no âmbito familiar e social.

Por fim, cabe ressaltar que os atores sociais de ambas as Escolas se referiram ao Massively Multiplayer Online Game - MMOG ${ }^{7}$ Second Life, que segundo Delwiche (2006) e Hew e Cheung (2010) apresenta um mundo virtual e uma simulação da vida cotidiana, demonstrando ser uma importante ferramenta de aprendizagem, que auxilia na alfabetização, melhora da atenção e desenvolvimento de um "pensar de nível superior".

Nessa dimensão a conformação cultural das novas gerações conduz a incorporação de conceitos e formas de vivências esportivas que os games esportivos trazem a sociedade. Cabe aos professores de Educação Física uma postura diante de tais processos, visto que não podem ser renegados da cultura lúdica infanto-juvenil atual.

\section{Considerações Finais}

O estudo mostra que os jogos eletrônicos são um relevante mecanismo de socialização, diversão e aprendizagem. Os games de futebol aparecem como preferidos entre os jogos eletrônicos de ação esportiva e relacionados à prática corporal desta modalidade, refletindo a conformação cultural brasileira do "país do futebol". Constatou-se também significativa influência dos games na cultura esportiva dos escolares e consequentemente na cultura corporal de movimento. Esta influência se mostrou próxima entre os estratos socioeconômicos, revelando que os esportes virtuais seguem o mesmo caminho dos esportes tradicionais, nos quais a paixão que une os torcedores leva a quase inexistência de barreiras sociais e culturais, algo que pensado na esfera da virtualização, possibilita apontar para um processo de humanização civilizatória da relação social total. Pois se antes o esporte unia por meio de seus jogadores, povos diversos em torno de si

\footnotetext{
7 Jogos de relacionamentos sociais no qual se simula outra realidade em ambientes virtuais semelhantes à sociedade atual.
}

Motriz, Rio Claro, v.17, n.4, p.600-609, out./dez. 2011 nos campeonatos mundiais, agora o esporte virtual une cada um dos ciberjogadores em qualquer parte do mundo, independentemente do credo, raça e divergência política, histórica e/ou social.

Há necessidade dos professores de Educação Física compreenderem o que ocorre na virtualização do esporte e do corpo, para que possam suplantar dificuldades nas relações com os alunos, bem como a reprodutibilidade de preconceitos e ordens de caráter cultural que possam levar a atitudes inaceitáveis para a boa convivência humana, como o nacionalismo, a discriminação de gênero, etnias, credos e o ódio, que podem ser passados subliminarmente aos sujeitos-jogadores nos games que obviamente seguem os ditames do mercado.

Espera-se que esta discussão possa tornar as aulas de Educação Física mais atraentes e de aprendizado potencializado tomando por base elementos da cultura lúdica infanto-juvenil a exemplo dos jogos eletrônicos. Pois assim, os novos delineamentos paradigmáticos que surgem para o movimento humano e sua representação científica por meio da Educação Física, possam ser aproximados do pensar, sentir e agir das novas gerações ciberculturais.

\section{Referências}

ABREU, C. N.; KARAM, R. G.; GÓES, D. S.; SPRITZER, D. T. Dependência de internet e de jogos eletrônicos: uma revisão. Revista

Brasileira de Psiquiatria, São Paulo, v. 30 n. 2, p. 156-67, 2008.

AGUILERA, M. D.; MENDIZ, A. Video games and education: education in the face of a "parallel school". ACM Computers in Entertainment, New York, v. 1, n. 1, p. 1-14, 2003. Disponível em: $<$ http://dl.acm.org/citation.cfm?id=950583\&bnc=1> . Acesso em: 25 abr. 2009.

ALVARENGA, P. Práticas educativas parentais como forma de prevenção de problemas de comportamento. In: GUIILHARDI, H. J. (Org.). Sobre comportamento e cognição: expondo a variabilidade. Santo André: Esetec, 2001. p. 5460.

AZEVEDO, T. Jogadores viram profissionais com a rede. Folha de São Paulo, São Paulo, 18 fev. 2004. Caderno Informática, p. 1-2. Disponível em: $<$ http://www1.folha.uol.com.br/fsp/indices/inde180 22004.htm>. Acesso em: 25 out. 2009. 
BARDIN, L. Análise de conteúdo. Lisboa: Edição 70, 2008.

BETTI, M. A janela de vidro: esporte, televisão e educação física. Campinas: Papirus, 1998.

BETTI, M. Educação Física e Sociologia: novas e velhas questões no contexto brasileiro. In: CARVALHO, Y. M.; RUBIO, K. (Orgs.). Educação Física e Ciências Humanas. São Paulo: Hucitec, 2001. p. 155-169.

BRASIL. Ministério da Saúde. Conselho Nacional de Saúde. Resolução 196/96. Aprova as diretrizes e normas regulamentadoras de pesquisas envolvendo seres humanos. Brasília, DF, 2003.

\section{BROUGÉRE, G. Brinquedo e Cultura. São}

Paulo: Cortez, 1995.

COSTA, A. Q.; BETTI, M. Mídias e Jogos: do virtual para uma experiência corporal educativa. Revista Brasileira de Ciências do Esporte, Campinas, v. 27, n. 2, p. 165-178, jan. 2006.

DAOLIO, J. Jogos esportivos coletivos: dos princípios operacionais aos gestos técnicos modelo pendular a partir das idéias de Claude Bayer. Revista Brasileira de Ciência e Movimento, Brasília, v. 10, n. 4, p. 99-103, 2002.

DELWICHE, A. Massively multiplayer online games (MMOs) in the new media classroom. Educational Technology and Society, Athabasca, v. 9, n. 3, p. 160-172, 2006. Disponível em: $<$ http://www.ifets.info/journals/9 3/14.pdf>. Acesso em: 09 jun. 2010.

ELIAS, N.; DUNNING, E. Deporte y ocio en el proceso de la civilización. México: FCE,1995.

FERES NETO, A. Videogame: jogo, narrativa ou esporte?: uma abordagem à luz das teorias do virtual. In: ENCONTRO NACIONAL DE RECREAÇÃO E LAZER, 18., 2006, Curitiba. Anais... Curitiba: [S.n.], 2006.

GAMA, D. R. N. Ciberatletas, cibercultura e jogos digitais: considerações epistemológicas. Revista

Brasileira de Ciências do Esporte, Campinas, v. 26, n. 2, p. 163-171, 2005a.

GAMA, D. R. N. Jogos no ciberespaço: reflexões sobre uma prática emergente de lazer a partir do imaginário social. Impulso, Piracicaba, v. 16, n. 39, p. 53-67, 2005b. Disponível em: $<$ http://www.unimep.br/phpg/editora/revistaspdf/im p39art04.pdf>. Acesso em: 20 fev. 2009.

NORTHWOODS Software Corporation. Godiagram express for .NET: Windows Forms.
Version 2.6.2. [S. I.]: Northwoods, 2007. 1 CDROM.

HENDERSON, S.; FEINER, S. Opportunistic tangible user interfaces for augmented reality. IEEE Transactions on Visualization and Computer Graphics, New York, v. 16, n. 1, p. 416, Jan./Feb. 2010. Disponível em: $<$ http://pesquisa.bvsalud.org/regional/resources $/ \mathrm{m}$ dl-19910657>. Acesso em: 01 fev. 2010.

HEROLD JUNIOR, C. Do corpo-motor ao corpoinformação: corporeidade e trabalho no capitalismo. Revista Brasileira de Ciências do Esporte, Campinas, v. 30, n. 2, p. 107-122, 2009.

HEW, K. F.; CHEUNG, W. S. Use of threedimensional (3-D) immersive virtual worlds in K-12 and higher education settings: a review of the research. British Journal of Educational Technology, London, v. 41, n. 1, p. 33-55, 2010. Disponível em: <http://dx.doi.org/10.1111/j.14678535.2008.00900.x>. Acesso em: 03 ago. 2010.

HOBSBAWM, E. Superioridade americana é fenômeno temporário. 30 set. 2007.

Entrevistadora: Sylvia Colombo. Folha de São Paulo, São Paulo, 30 set. 2007. Caderno Mundo. Disponível em:

$<$ http://www1.folha.uol.com.br/folha/mundo/ult94u 332395.shtml>. Acesso em: 23 Dez. 2009.

HUBER, G. L.; GÜRTLER, L. AQUAD 6: el programa para analizar datos cualitativos. Versão 6.7.1.1. [S.I.]: [s.n.], 2008. 1 CD-ROM.

JIN, S. A. Does imposing a goal always improve exercise intentions in avatar-based exergames? The moderating role of interdependent selfconstrual on exercise intentions and selfpresence. Cyberpsychology, behavior and social networking, New Rochelle, v. 13, n. 3, p. 335-339, Jun. 2010. Disponível em: <http://dx.doi.org/10.1089/cyber.2009.0186>. Acesso em: 03 set. 2010.

LEMOS, A. Cibercultura: alguns pontos para compreender a nossa época. In: LEMOS, A.; CUNHA, P. (Orgs.). Olhares sobre a cibercultura. Porto Alegre: Sulina, 2003. p. 1123.

LÉVY, P. O que é o virtual? 3. ed. reimp. São Paulo: Ed. 34, 1996.

LÉVY, P. Cibercultura. São Paulo: Editora 34, 1999.

MARK, A. E.; JANSSEN, I. Relationship between screen time and metabolic syndrome in adolescents. Journal of Public Health (Oxf), London, v. 30, n. 2, p. 153-60, 2008. Disponível em: 
<http://jpubhealth.oxfordjournals.org/cgi/reprint/30/ 2/153 >. Acesso em: 12 jan. 2009.

MOITA, F. M. G. da S. C. Games: contexto cultural e curricular juvenil. 2006. 181f. Tese (Doutorado em Educação) - Universidade Federal da Paraíba, João Pessoa, 2006.

MURAD, M. Sociologia e Educação Física: diálogos, linguagens do corpo, esportes. Rio de Janeiro: FGV, 2009.

PEREIRA, R. S. O lazer na cibercidade. In: ENCONTRO NACIONAL DE RECREAÇÃO E LAZER, 18., 2006, Curitiba. Anais... Curitiba: [S.n.], 2006.

PIAGET, J. O juízo moral na criança. 3 ed. São Paulo: Summus, 1994.

REIS, L. J. de A.; CAVICHIOLLI, F. R. Jogos eletrônicos e a busca da excitação. Movimento, Porto Alegre, v. 14, n. 3, p. 163-183, set./dez. 2008. Disponível em:

$<$ http://www.seer.ufrgs.br/Movimento/article/downl oad/2225/4182>. Acesso em: 13 fev. 2010.

RINALDI, A. E. M.; PEREIRA, A. F.; MACEDO, C. S.; MOTA, J. F.; BURINI, R. C. Contribuições das práticas alimentares e inatividade física para o excesso de peso infantil. Revista Paulista de Pediatria, São Paulo, v. 26, n. 3, p. 271-277, 2008. Disponível em:

$<$ http://www.scielo.br/scielo.php?script=sci arttext \&pid=S0103-05822008000300012\&lang=pt>. Acesso em: 22 jan. 2009.

ROSENBERG, D.; DEPP, C. A.; VAHIA, I. V.; REICHSTADT, J.; PALMER, B. W.; KERR, J.; NORMAN, G.; JESTE, D. V. Exergames for subsyndromal depression in older adults: a pilot study of a novel intervention. American Journal of Geriatric Psychiatry, Washington, v. 18, n. 3, p. 212-220, Mar. 2010. Disponível em: $<$ http://dx.doi.org/10.1097/JGP.0b013e3181b7f10 è $>$. Acesso em: 29 jan. 2010.

SANTAELLA, L. Corpo e comunicação: sintomas da cultura. São Paulo: Paulus, 2004.

\section{SÉRGIO, M. Para uma epistemologia da} motricidade humana. Lisboa: Compendium, 2000.

SETZER, V. W. Efeitos negativos dos meios eletrônicos em crianças, adolescentes e adultos. São Paulo: [S.n.], 2008. Disponível em: $<$ http://www.ime.usp.br/ vwsetzer/efeitosnegativos-meios.html>. Acesso em: 03 mar. 2010.

SPSS. SPSS for Windows 10: statistical package for the social sciences. Version 10.0. [S.I.]: SPSS Inc., 2000. 1 CD-ROM.
TURKLE, S. The second self: computers and the human. Cambridge: MIT Press, 2005.

VASQUES, D. G.; LOPES, A. S. Fatores associados à atividade física e aos comportamentos sedentários em adolescentes. Revista Brasileira de Cineantropometria e Desempenho Humano, Florianópolis, v. 11, n. 1, p. 59-66, 2009.

WEBER, L. N. D.; SALVADOR, A. P. V. Práticas educativas parentais: um estudo comparativo da interação familiar de dois adolescentes distintos. Interação em Psicologia, Curitiba, v. 9, n. 2, p. 341-353, jul./dez. 2005.

Agradecimento: Coordenação de Aperfeiçoamento de Pessoal de Nível Superior CAPES, pelo financiamento sob a forma de bolsa de mestrado.

Este artigo é derivado da dissertação de mestrado "A virtualização esportiva nos jogos eletrônicos e os novos paradigmas para o movimento humano", do primeiro autor sob orientação da segunda autora.

Endereço:

Bruno Medeiros Roldão de Araújo

Rua Otacílio Nepomuceno, 470 Catolé

Campina Grande PB Brasil

58410-160

Telefone: (83) 3337.1997

Celular: (83) 8809.5142 / (83) 9948.0396

e-mail: bruno.mr.araujo@ufcg.edu.br

Recebido em: 10 de setembro de 2010. Aceito em: 13 de abril de 2011.

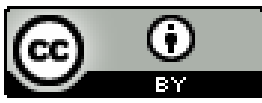

Motriz. Revista de Educação Física. UNESP, Rio Claro, SP, Brasil - elSSN: 1980-6574 - está licenciada sob Creative Commons - Atribuição 3.0 